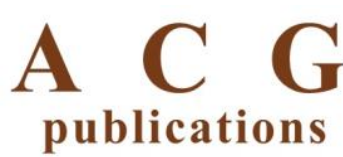

Rec. Nat. Prod. 14:3 (2020) 166-170

records of natural

products

\title{
New Aromadendrane Sesquiterpenoid Pseuboydone F from the Marine-derived Fungus Pseudallescheria boydii F44-1
}

\author{
Mei-Xiang Yuan ${ }^{1}$, Qi Guo ${ }^{1}$, Yan-Qin Ran ${ }^{2}$, Yi Qiu ${ }^{1}$, \\ Wen-Jian Lan ${ }^{3}$ and Hou-Jin $\mathrm{Li} 1{ }^{1}$, * \\ ${ }^{1}$ School of Chemistry, Sun Yat-sen University, Guangzhou 510275, P. R. China \\ ${ }^{2}$ School of Traditional Chinese Medicine, Guangdong Pharmaceutical University, Guangzhou 510006, \\ P. R. China \\ ${ }^{3}$ School of Pharmaceutical Sciences, Sun Yat-sen University, Guangzhou 510006, P. R. China
}

(Received July 20, 2019; Revised September 04, 2019; Accepted September 13, 2019)

\begin{abstract}
A new aromadendrane sesquiterpenoid pseuboydone F (1), along with a known pseuboydone A (2), were isolated from the marine-derived fungus Pseudallescheria boydii F44-1 associated with the soft coral Sarcophyton sp.. The structures were elucidated by HRMS, 1D and 2D NMR spectroscopic data.
\end{abstract}

Keywords: Marine fungus; Pseudallescheria boydii; aromadendrane; sesquiterpenoid; pseudboydone F. (C) 2020 ACG Publications. All rights reserved.

\section{Introduction}

Marine-derived fungi are considered as a promising source of novel natural products with biodiversity and chemical diversity. Although numerous novel metabolites have been obtained from a large number of marine-derived fungi, actually the discovering rate is still not high. It's challengeable to develop efficient dereplication techniques based on NMR or MS analysis [1,2]. In our previous studies, we reported the strategies to increase the discovery rate of new compounds by tracking the diagnostic ${ }^{1} \mathrm{H}$ or ${ }^{13} \mathrm{C}$ NMR resonance signals. For example, a pair of unprecedented epimonothiodiketopiperazine diastereomers, pseudellones A and B were isolated from the marine fungus Pseudallescheria ellipsoidea by tracking the relatively rare ${ }^{1} \mathrm{H}$ NMR resonated signals in the range of 8.00-8.50 ppm [3]. Following with the rich aromatic proton signals in aromatic range of 6.5$8.5 \mathrm{ppm}, 14$ new alkaloids were obtained from marine-derived fungus Scedosporium apiospermum F41-1 [4].

Recently, we have isolated a fungal strain Pseudallescheria boydii (collection No. F44-1) from the soft coral Sarcophyton sp. collected in the Hainan Sanya National Coral Reef Reserve, China. This fungus was cultured in glucose-peptone-yeast extract (GPY) media and prescreened the metabolites extract using the ${ }^{1} \mathrm{H}$ NMR spectroscopy. At the high field area, two sets of signals at $\delta_{\mathrm{H}} 0.50$ (dd, 9.6, 9.6) and $\delta_{\mathrm{H}} 0.17(\mathrm{dd}, 9.6,9.6)$ attracted our attention. To the best of our knowledge, the aromadendrane sesquiterpenoids showed the signals in the range of 0-0.6 ppm due to the shielding

*Corresponding author: E-Mail: ceslhj@ mail.sysu.edu.cn; Phone: 86-20-84113698; Fax: 86-20-84112245 
effect of the cyclopropane ring. Previously, by tracking the proton resonance signals in this region, the aromadendrane sesquiterpenoids pseuboydones A and B were separated from marine-derived fungus Pseudallescheria boydii F19-1[5], and scedogiines A-F were isolated from the marine-derived fungus Scedosporium dehoogii F41-4 [6]. Using the same strategy, a new aromadendrane sesquiterpenoid pseuboydone F (1) and a known pseuboydone A (2) (Figure 1) were isolated from the fungus Pseudallescheria boydii F44-1. Herein we report the isolation and structural elucidation of these compounds.

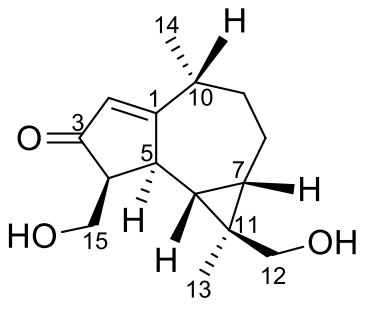

1

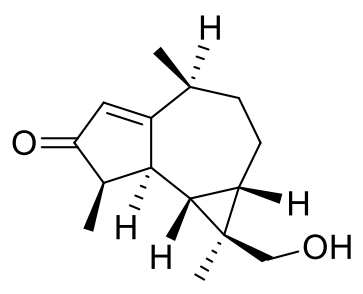

2

Figure 1. The chemical structures of compounds 1 and $\mathbf{2}$

\section{Materials and Methods}

\subsection{General Experimental Procedures}

Preparative HPLC was performed using a Shimadzu LC-20AT HPLC pump (Shimadzu Corporation, Nakagyo-ku, Kyoto, Japan) and installed with an SPD-20A dual $\lambda$ absorbance detector (Shimadzu Corporation, Nakagyo-ku, Kyoto, Japan) and a Capcell-Pak C18 UG80 HPLC column (250 mm $\times 20 \mathrm{~mm}$, Shiseido, Japan). 1D and 2D NMR experiments were measured with Bruker Avance 400 spectrometers and Bruker Avance 600 spectrometers. The chemical shifts are relative to the residual solvent signal $\left(\mathrm{CDCl}_{3}: \delta_{\mathrm{H}} 7.26\right.$ and $\left.\delta_{\mathrm{C}} 77.0\right)$. The HR-APCI-MS spectrum was measured with Thermo Obitrap Fusion Lumos liquid chromatography-mass spectrometry.

\subsection{Fungal Identification and Culture Method}

The marine fungus Pseudallescheria boydii (collection number F44-1) was isolated from the inner tissue of the soft coral Sarcophyton sp. collected from Hainan Sanya National Coral Reef Reserve, P. R. China. This fungal strain was conserved in 15\% (v/v) glycerol aqueous solution at -80 ${ }^{\circ} \mathrm{C}$. A voucher specimen was deposited in the School of Chemistry, Sun Yat-sen University, Guangzhou, P. R. China. Analysis of the ITS rDNA by BLAST database screening provided $99.9 \%$ match to Pseudallescheria boydii. The marine fungus Pseudallescheria boydii F44-1, was cultured in the GPY medium which included $15 \mathrm{~g} / \mathrm{L}$ glucose, $5 \mathrm{~g} / \mathrm{L}$ peptone, $2 \mathrm{~g} / \mathrm{L}$ yeast extract, $25 \mathrm{~g} / \mathrm{L}$ sea salt, and $1 \mathrm{~L} \mathrm{H}_{2} \mathrm{O}$ at $\mathrm{pH}$ 7.0. Fungal mycelia were cut and transferred aseptically to $1000 \mathrm{~mL}$ conical flasks each containing $600 \mathrm{~mL}$ sterilized liquid medium. The fungus was incubated at $28^{\circ} \mathrm{C}$ for 20 days.

\subsection{Extraction and Isolation}

10 liters culture broth was filtered through cheesecloth. The liquid was successively extracted three times with EtOAc $(3 \times 10 \mathrm{~L})$. Finally, the extract was concentrated by low-temperature rotary evaporation to get a crude extract $(2.8 \mathrm{~g})$. The extract was chromatographed on a silica gel column (diameter: $4 \mathrm{~cm}$, length: $50 \mathrm{~cm}$, silica gel, $35 \mathrm{~g}$ ) with a gradient of petroleum Ether-EtOAc (30:0-0:30, $\mathrm{v} / \mathrm{v})$ followed by EtOAc-MeOH (30:0-0:30, v/v) to yield ten fractions (Fr.1-Fr.10). The fractions were monitored by TLC and similar fractions, Fr.6-Fr.8 were combined and concentrated in vacuo, and then, the constituents was purified by silica gel column using a step gradient elution with ether-EtOAc $(10: 0-0: 10, \mathrm{v} / \mathrm{v})$ to get 10 subfractions (Fr.6-8-1 to Fr.6-8-10). Then Fr.6-8-5 was further purified using reversed phase preparative HPLC with a mobile phase of $\mathrm{CH}_{3} \mathrm{CN}-\mathrm{H}_{2} \mathrm{O}\left(60: 40, \mathrm{v} / \mathrm{v}, \mathrm{t}_{\mathrm{R}}=30 \mathrm{~min}\right)$ to obtain compound $\mathbf{1}(1.2 \mathrm{mg})$. Further HPLC purification of Fr.6-8-6 with $\mathrm{CH}_{3} \mathrm{OH}-\mathrm{H}_{2} \mathrm{O}(75: 25$, v/v, $\left.\mathrm{t}_{\mathrm{R}}=37.5 \mathrm{~min}\right)$ gave compound $2(3.9 \mathrm{mg})$. 


\section{Results and Discussion}

\subsection{Structure Elucidation}

Pseudboydone F (1) was obtained as a pale yellow oil. The molecular formula was determined to be $\mathrm{C}_{15} \mathrm{H}_{22} \mathrm{O}_{3}$ by the HR-APCI-MS peak at $\mathrm{m} / z$ 249.14906 [M-H] ${ }^{-}$(calcd $\mathrm{C}_{15} \mathrm{H}_{21} \mathrm{O}_{3}, 249.14962$ ) indicating five degrees of unsaturation. The ${ }^{13} \mathrm{C}$ NMR and DEPT spectra displayed two sp ${ }^{2}$ quaternary carbons, one $\mathrm{sp}^{3}$ quaternary carbon, one $\mathrm{sp}^{2}$ methine, five $\mathrm{sp}^{3}$ methines, four $\mathrm{sp}^{3}$ methylenes and two methyls (Table 1). The ${ }^{1} \mathrm{H}^{-1} \mathrm{H}$ COSY correlations of $\mathrm{H}_{2}-15 / \mathrm{H}-4 / \mathrm{H}-5 / \mathrm{H}-6 / \mathrm{H}-7 / \mathrm{H}_{2}-8 / \mathrm{H}_{2}-9 / \mathrm{H}-10 / \mathrm{H}_{3}-14$ revealed the fragment $-\mathrm{CH}_{2}-\mathrm{CH}-\mathrm{CH}-\mathrm{CH}-\mathrm{CH}-\mathrm{CH}_{2}-\mathrm{CH}_{2}-\mathrm{CH}-\mathrm{CH}_{3}$ (Figure 2). In the ${ }^{1} \mathrm{H}$ NMR spectrum, two characteristic signals at $\delta_{\mathrm{H}} 0.50$ (dd, 9.6, 9.6, H-6) and 0.87 (ddd, 11.4, 9.6, 6.2, H-7) (Table 1) displayed the existence of a cyclopropane ring. One carbonyl group $\left(\delta_{\mathrm{C}} 210.7, \mathrm{C}-3\right)$ and a trisubstituted double bond $\left(\delta_{\mathrm{C}} 190.3, \mathrm{C}-1 ; 126.6, \mathrm{C}-2\right)$ illustrated two degrees of unsaturation. So, compound 1 had to contain another two rings. Further analysis of the HMBC correlations from $\mathrm{H}-2$ to C-4 and C-5, from $\mathrm{H}_{3}-14$ to C-1, the olefinic quaternary carbon C-1 was connected to C-5 $\left(\delta_{\mathrm{C}} 44.0\right)$ forming a bridge. A five-membered ring system was constructed by quaternary carbon $\mathrm{C}-1$ and methine C-4 $\left(\delta_{\mathrm{C}} 57.9\right)$ via carbonyl group C-3. Therefore, compound 1 contains a five- and sevenmembered rings and cyclopropane fused ring system, which belong to aromadendrane sesquiterpenoid. In addition, one oxygenated methylene and one methyl connected with $\mathrm{C}-11\left(\delta_{\mathrm{C}}\right.$ 27.4), which was confirmed by the HMBC correlations from $\mathrm{H}_{2}-12$ to $\mathrm{C}-6, \mathrm{C}-7$ and $\mathrm{C}-11$, from $\mathrm{H}_{3}-13$ to $\mathrm{C}-11$ and $\mathrm{C}-12$. The remaining one oxygenated methylene $\mathrm{C}-15$ was attached to the $\mathrm{C}-4$ position based on the HMBC correlations from $\mathrm{H}_{2}-15$ to C-4 and C-5.

Table 1. ${ }^{1} \mathrm{H}$ and ${ }^{13} \mathrm{C}$ NMR data of compounds 1 and 2 in $\mathrm{CDCl}_{3}(\delta$ in ppm, $J$ in $\mathrm{Hz})$.

\begin{tabular}{|c|c|c|c|c|}
\hline \multirow[t]{2}{*}{ No. } & \multicolumn{2}{|r|}{$\mathbf{1}^{\mathrm{a}}$} & \multicolumn{2}{|r|}{$2^{b}$} \\
\hline & $\delta_{\mathrm{C}}$ & $\delta_{\mathrm{H}}$ & $\delta_{\mathrm{C}}$ & $\delta_{\mathrm{H}}$ \\
\hline 1 & 190.3, C & & 187.7, C & \\
\hline 2 & 126.6, CH & $5.86(\mathrm{~d}, 1.2)$ & $125.2, \mathrm{CH}$ & $5.81(\mathrm{~s})$ \\
\hline 3 & 210.7, C & & $211.5, \mathrm{C}$ & \\
\hline 4 & $57.9, \mathrm{CH}$ & $2.50(\mathrm{dd}, 6.6,6.6)$ & $46.7, \mathrm{CH}$ & $2.60(\mathrm{~m})$ \\
\hline 5 & $44.0, \mathrm{CH}$ & $2.45(\mathrm{~d}, 9.6)$ & $44.3, \mathrm{CH}$ & $2.60(\mathrm{~m})$ \\
\hline 6 & $28.5, \mathrm{CH}$ & $0.50(\mathrm{dd}, 9.6,9.6)$ & $25.2, \mathrm{CH}$ & $0.17(\mathrm{dd}, 9.6,9.6)$ \\
\hline 7 & $25.7, \mathrm{CH}$ & $0.87(\mathrm{ddd}, 11.4,9.6,6.2)$ & $25.0, \mathrm{CH}$ & $0.83(\mathrm{~m})$ \\
\hline \multirow[t]{2}{*}{8} & $23.5, \mathrm{CH}_{2}$ & $1.27(\mathrm{~m})$ & $23.2, \mathrm{CH}$ & $1.24(\mathrm{~m})$ \\
\hline & & $2.07(\mathrm{ddd}, 14.4,6.6,6.2)$ & & $2.06(\mathrm{~m})$ \\
\hline \multirow[t]{2}{*}{9} & $35.1, \mathrm{CH}_{2}$ & $1.44(\mathrm{ddd}, 12.6,12.6,12.0)$ & $35.8, \mathrm{CH}_{2}$ & $1.36(\mathrm{~m})$ \\
\hline & & $1.97(\mathrm{ddd}, 12.6,6.6,6.6)$ & & $2.00(\mathrm{~m})$ \\
\hline 10 & $40.7, \mathrm{CH}$ & $2.35(\mathrm{ddq}, 12.6,6.6,6.6)$ & $40.2, \mathrm{CH}$ & $2.34(\mathrm{~m})$ \\
\hline 11 & 27.4, C & & 26.7, C & \\
\hline \multirow[t]{2}{*}{12} & $72.6, \mathrm{CH}_{2}$ & $3.29(\mathrm{~d}, 10.8)$ & $72.3, \mathrm{CH}_{2}$ & $3.24(\mathrm{~d}, 10.8)$ \\
\hline & & $3.39(\mathrm{~d}, 10.8)$ & & $3.43(\mathrm{~d}, 10.8)$ \\
\hline 13 & $11.4 \mathrm{CH}_{3}$ & $1.24(\mathrm{~s})$ & $11.5, \mathrm{CH}_{3}$ & $1.20(\mathrm{~s})$ \\
\hline 14 & $20.1, \mathrm{CH}_{3}$ & $1.26(\mathrm{~d}, 6.6)$ & $19.7, \mathrm{CH}_{3}$ & $1.24(\mathrm{~d}, 6.8)$ \\
\hline \multirow[t]{2}{*}{15} & $63.4, \mathrm{CH}_{2}$ & $3.69(\mathrm{dd}, 10.2,6.6)$ & $10.0, \mathrm{CH}_{3}$ & $1.13(\mathrm{~d}, 6.4)$ \\
\hline & & $3.76(\mathrm{dd}, 10.2,6.6)$ & & \\
\hline
\end{tabular}

The relative configuration of compound 1 was established by analysis the NOESY spectrum. The cross peaks of $\mathrm{H}-6 / \mathrm{H}-7, \mathrm{H}-6 / \mathrm{H}_{2}-12, \mathrm{H}-6 / \mathrm{H}_{2}-15$, and $\mathrm{H}-7 / \mathrm{H}_{2}-12$, implied that $\mathrm{H}-6, \mathrm{H}-7, \mathrm{H}_{2}-12$ and $\mathrm{H}_{2}-15$ having the same $\beta$-oriented. The NOE interactions of $\mathrm{H}-5 / \mathrm{H}_{3}-13$ and $\mathrm{H}-5 / \mathrm{H}_{3}-14$ suggested $\mathrm{H}-5$, $\mathrm{H}_{3}-13$ and $\mathrm{H}_{3}-14$ had an $\alpha$-orientation. 

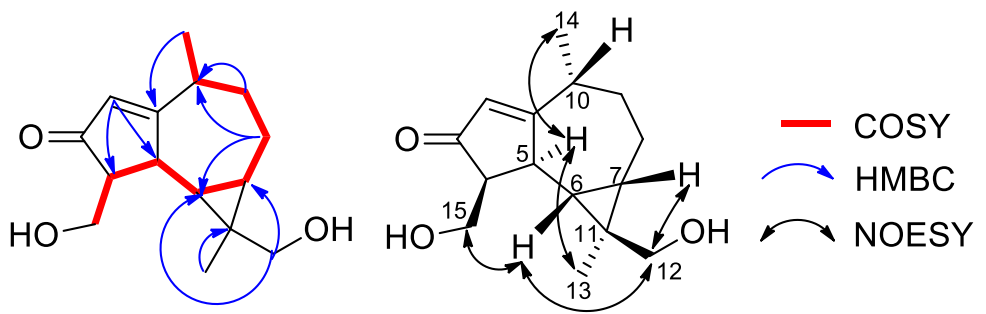

Figure 2. ${ }^{1} \mathrm{H}-{ }^{1} \mathrm{H}$ COSY, key HMBC and key NOESY correlations of $\mathbf{1}$

Followed the triplet at $\delta_{\mathrm{H}} 0.17$ (dd, 9.6, 9.6), compound 2 was purified. By comparing its NMR data with the literature values, compound 2 was identified as pseuboydone A [5].

\subsection{Cytotoxicity}

Seven cancer cell lines, including CNE1, CNE2, HONE1, SUNE1, A549, GLC82 and HL7702 were used to examine the cytotoxic activities of compounds $\mathbf{1}$ and $\mathbf{2}$ in vitro. This assay revealed that $\mathbf{1}$ and $\mathbf{2}$ were apparently inactive $\left(\mathrm{IC}_{50}\right.$ values $\left.>100 \mu \mathrm{M}\right)$.

\section{Acknowledgments}

This work was financially supported by the National Natural Science Foundation of China (No. 81872795), Guangdong Provincial Science and Technology Research Program (No. 2016A020222004), Natural Science Foundation of Guangdong Province (No. 2018A030313157), and the National Science and Technology Major Project for New Drug Innovation and Development (No. 2017ZX09305010).

\section{Supporting Information}

Supporting information accompanies this paper on http://www.acgpubs.org/journal/records-ofnatural-products

\section{ORCID}

Mei-Xiang Yuan: $\underline{0000-0002-0151-8325}$

Qi Guo: 0000-0003-0573-8031

Yan-Qin Ran: 0000-0002-9570-673X

Yi Qiu: 0000-0001-6327-1770

Wen-Jian Lan: 0000-0002-2759-8394

Hou-Jin Li: 0000-0003-3026-6128

\section{References}

[1] F. Bucar, A. Wube and M. Schmid (2013). Natural product isolation - how to get from biological material to pure compounds, Nat. Prod. Rep. 30, 525-545.

[2] J. Hubert, J. M. Nuzillard and J. H. Renault (2017). Dereplication strategies in natural product research: how many tools and methodologies behind the same concept?, Phytochem. Rev. 16, 55-95.

[3] W. Liu, H. J. Li, M. Y. Xu, Y. C. Ju, L. Y. Wang, J. Xu, D. P. Yang and W. J. Lan (2015). Pseudellones A-C, three alkaloids from the marine-derived fungus Pseudallescheria ellipsoidea F42-3, Org. Lett. 17, 5156-5159.

[4] L. H. Huang, M. Y. Xu, H. J. Li, J. Q. Li, Y. X. Chen, W. Z. Ma, Y. P. Li, J. Xu, D. P. Yang and W. J. Lan (2017). Amino acid-directed strategy for inducing the marine-derived fungus Scedosporium apiospermum F41-1 to maximize alkaloid diversity, Org. Lett. 19, 4888-4891.

[5] W. J. Lan, K. T. Wang, M. Y. Xu, J. J. Zhang, C. K. Lam, G. H. Zhong, J. Xu, D. P. Yang, H. J. Li and L. Y. Wang (2016). Secondary metabolites with chemical diversity from the marine-derived fungus 
Pseudallescheria boydii F19-1 and their cytotoxic activity, RSC Adv. 6, 76206-76213.

[6] K. C. Hu, M. Y. Xu, H. J. Li, J. Yuan, G. Tang, J. Xu, D. P. Yang and W. J. Lan (2016). Discovery of aromadendrane anologues from the marine-derived fungus Scedosporium dehoogii F41-4 by NMRguided isolation, $R S C A d v$. 6, 94763-94770.

\section{A C G \\ publications \\ (c) 2020 ACG Publications}

